\title{
Establishment and functions of DNA methylation in the germline
}

\begin{abstract}
Epigenetic modifications established during gametogenesis regulate transcription and other nuclear processes in gametes, but also have influences in the zygote, embryo and postnatal life. This is best understood for DNA methylation which, established at discrete regions of the oocyte and sperm genomes, governs genomic imprinting. In this review, we describe how imprinting has informed our understanding of de novo DNA methylation mechanisms, highlight how recent genome-wide profiling studies have provided unprecedented insights into establishment of the sperm and oocyte methylomes and consider the fate and function of gametic methylation and other epigenetic modifications after fertilization.
\end{abstract}

First draft submitted: 11 May 2016; Accepted for publication: 20 July 2016; Published online: 23 September 2016

Keywords: DNA methylation $\bullet$ embryo $\bullet$ imprinting $\bullet$ oogenesis $\bullet$ spermatogenesis

- transgenerational inheritance

Epigenetic marks are a fundamental component of the mechanisms that functionally interpret DNA sequence. These marks contribute to the establishment and maintenance of specialized gene expression patterns that determine cell identity. Epigenetically reinforced transcriptional states can be propagated through cell division, acting as a longterm marker of developmental origin during lineage specification. DNA methylation is an epigenetic mark that can be established de novo, maintained through cell division and be interpreted by transcription machinery and DNA-binding proteins. It is a repressive mark that characterizes heterochromatin in mammalian cells, and when found at gene promoters DNA methylation generally suppresses transcription [1].

DNA methylation involves the transfer of a methyl group from S-adenosyl-L-methionine to a cytosine residue [2]. The process is catalyzed by DNA methyltransferases in two distinct modes. During cell division, replication of a methylated DNA sequence creates hemimethylated $\mathrm{CpG}$ dinucleotides, where methylation is found only on the original strand and is absent from the newly synthesized strand. Hemimethylated CpGs attract the maintenance methyltransferase DNMT1, which methylates the unmethylated strand to restore symmetric DNA methylation [3-6]. In contrast, the de novo methyltransferases DNMT3A and DNMT3B methylate CpGs unmethylated on both DNA strands [7]. The related protein DNMT3L lacks a catalytic domain but acts as a crucial cofactor of both DNMT3A and DNMT3B [8-12].

DNA methylation establishment in the germline is of particular importance, as methylation marks established in the gametes have the potential to regulate gene expression in the next generation. Imprinted loci are the paradigm for this inter-generational mode of gene regulation. Failure to establish correct germline-specific DNA methylation patterns has serious consequences for post-fertilization development. However, the mechanisms that target de novo
Epigenomics

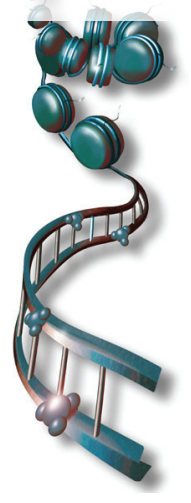

Kathleen R Stewart ${ }^{\ddagger 1,1,2}$, Lenka Veselovska ${ }^{\ddagger 1,1,3}$ \& Gavin Kelsey*,1

'Epigenetics Programme, The Babraham Institute, Cambridge, CB22 3AT, UK ${ }^{2}$ Biotech Research \& Innovation Centre (BRIC), University of Copenhagen, DK2200 Copenhagen, Denmark ${ }^{3}$ Laboratory of Developmental Biology \& Genetics, Department of Molecular Biology, University of South Bohemia, 37005 České Budějovice, Czech Republic *Author for correspondence:

Tel.: +44 1223496332 Fax: +44 1223496034 gavin.kelsey@babraham.ac.uk ${ }^{\ddagger}$ Authors contributed equally 
methylation in the germline are not fully understood. In this review, we will highlight recent advances in elucidating the mechanisms that direct de novo methylation in the germline, particularly in the female germline, and will review current knowledge of the roles of gametic DNA methylation in gametogenesis and post-fertilization development.

\section{DNA methylation in genomic imprinting}

Initially, DNA methylation in gametes was studied largely from the point of view of imprinted germline differentially methylated regions (gDMRs), or imprinted gDMRs. Imprinted gDMRs are loci that are methylated in either the female (maternally imprinted) or the male (paternally imprinted) germline, and that retain this monoallelic methylation in a parentof-origin specific manner following fertilization [13]. In somatic cells, the maternal and paternal alleles of imprinted loci have different epigenetic landscapes, composed of distinct DNA methylation profiles, histone post-translational modifications and regulation by noncoding RNAs. Human and mouse are the two most extensively used models for imprinting studies, although genomic imprinting is also found and wellcharacterized in flowering plants [14]. Imprinted loci represent a unique mode of epigenetic regulation, and a number of human congenital disorders are caused by loss of imprinting, making genomic imprinting a valuable model for both basic and translational research questions [15].

In mouse, there are 23 definitive and 11 putative maternally imprinted gDMRs [16] and three paternally imprinted gDMRs [13]. Maternally imprinted gDMRs fall within a category of CpG-rich genomic regions called $\mathrm{CpG}$ islands (CGIs), while the paternal gDMRs have $\mathrm{CpG}$ densities closer to the genome average (Figure 1) $[17,18]$. The vast majority of CpG dinucleotides in most cell types are methylated, but the

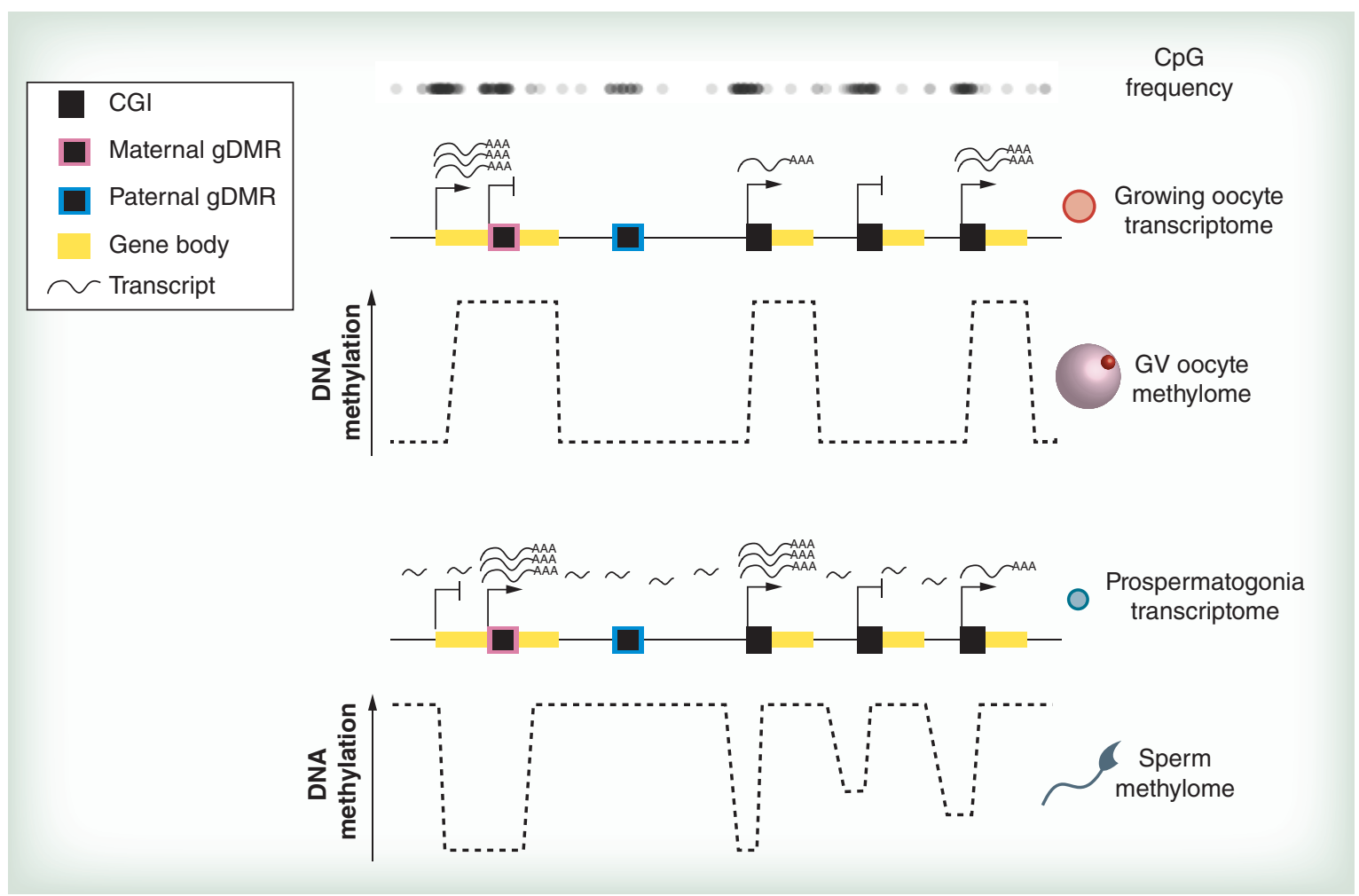

Figure 1. The oocyte and sperm methylomes. Methylated regions in the GV oocyte (top) tightly correspond with active transcription units in growing oocytes, initiating from both CGI and non-CGI transcription start sites. CGIs that become de novo methylated in oocytes, including maternally imprinted gDMRs, tend to be within active transcription units and $\mathrm{CpG}$-rich. In the male germline, regions that were both transcribed and untranscribed in prospermatogonia are methylated in mature sperm (bottom). Promoters of genes with weak or no expression in prospermatogonia display intermediate methylation in sperm, from either heterogeneous methylation of these regions in the germ cell pool or methylation heterogeneity in individual $\mathrm{CpGs}$ at these genomic regions. Paternally imprinted gDMRs tend to be less CpG-dense than maternally imprinted gDMRs. Notably, in either germline, transcription levels past a low threshold result in full methylation of the transcription unit, but active promoters at CGIs are protected from DNA methylation. Arrows, active transcription start sites; crosses, inactive transcription start sites.

CGI: CpG island; gDMR: Germline differentially methylated region; GV: Germinal vesicle. 
CpGs that comprise CGIs are exceptions to this rule and remain unmethylated in most cellular contexts. Functionally, CGIs are found at the majority of mammalian gene promoters, and their resistance to DNA methylation allows the RNA polymerase complex and relevant transcription factors to access the transcription start sites of genes [19]. Although CGIs canonically lack DNA methylation, in a typical mammalian cell a small proportion of these loci are fully methylated, often in a tissue-specific manner [20-22]. The CGIs that gain methylation within a particular cell type are most often intragenic, and are found within an actively transcribed gene [23]. The propensity for a CGI to gain methylation is also influenced by its $\mathrm{CpG}$ density, GC content and enrichment for transcription factor-binding motifs [24-27].

Prior to the advent of genome-wide analyses, the general assumption was that imprinted gDMRs were specifically targeted in the germline by specialized de novo methylation machinery, and research efforts were concentrated on searching for features that distinguished these regions from the rest of the genome. Genome-wide methylation studies have led to a reappraisal of this view. Specifically, comparing the oocyte and sperm methylomes revealed the existence of many more regions of differential methylation between the gametes than the classic imprinted gDMRs [28,29]. We will refer to these additional regions as nonimprinted gDMRs. In addition to the maternally imprinted gDMRs, the oocyte methylome contains many additional methylated but nonimprinted CGIs, which have a similar sequence composition to the imprinted CGIs. Similarly, the paternally imprinted gDMRs do not seem to be distinct from many of the other genomic regions that are methylated in sperm $[28,29]$. Therefore, rather than being uniquely targeted for DNA methylation, it is now thought that imprinted gDMRs gain methylation in the same manner as analogous regions in the genome (Figure 1). The distinguishing feature of imprinted gDMRs compared with nonimprinted gDMRs, then, is that the differential methylation at imprinted gDMRs persists following fertilization and epigenetic reprogramming in the early embryo, while the differential methylation at nonimprinted gDMRs does not [13]. What remains unclear is exactly how the differential patterns of DNA methylation that give rise to imprinted and nonimprinted gDMRs are established in sperm and oocytes.

\section{DNA methylation establishment in gametes} Timing of DNA methylation establishment

At the time of sex determination in the fetal gonads, which in mice occurs at around embryonic day 12.5 (E12.5), global DNA methylation levels are very low, and the methylomes of male and female primordial germ cells (PGCs) are very similar [30,31]. However, de novo methylation establishment proceeds in very different manners in the male and female germlines. In the male germline, de novo methylation is initiated at embryonic day E13.5, in prospermatogonia or gonocytes that are arrested in mitosis, and the male methylome is completely established prior to birth (Figure 2) [31-33]. Following methylation establishment, male gametes experience a proliferative burst before entering meiosis and beginning the process of differentiating into sperm. Therefore, the mature sperm methylome is a product of DNA methylation maintenance that must operate faithfully from birth in male mice.

In contrast, de novo methylation is not initiated until after birth in the female germline. In oocytes, DNA methylation establishment occurs in parallel with the follicular growth phase of oogenesis and is largely complete by the germinal vesicle stage, at approximately P21 in mice [28]. Several studies have demonstrated that DNA methylation establishment, at least at imprinted gDMRs, is coordinated with oocyte growth, and loci gain methylation at different stages of growth in a regulated manner (Figure 2) [34-36]. The function and mechanisms underlying this asynchronous DNA methylation establishment in oocytes remain unclear, and whether or not the paternally imprinted gDMRs are similarly methylated in coordination with spermatogenesis progression has not been extensively studied. Oocytes are arrested in meiotic prophase I throughout the growth phase, and do not resume meiosis until ovulation. Therefore, de novo methylation occurs on a nonreplicating genome in both the male and female germlines, but only the oocyte methylome is solely reflective of de novo methylation events.

\section{Mechanisms underlying DNA methylation establishment}

Between the male and female germlines, the male provides much more starting material for analysis. Additionally, unlike in oocytes, loss of DNA methylation during spermatogenesis causes infertility accompanied by a profound reduction in testis size, making factors important in DNA methylation establishment in the paternal germline readily identifiable. Methylation establishment during spermatogenesis has therefore been extensively studied using standard molecular and genetic approaches, and the mechanisms underlying de novo methylation in male germ cells are well characterized. DNA methylation establishment in male germ cells is initiated at repetitive sequences by a testisspecific class of small RNAs called PIWI-interacting RNAs, or piRNAs. These piRNAs are derived from repeat sequences and direct methylation and silencing 


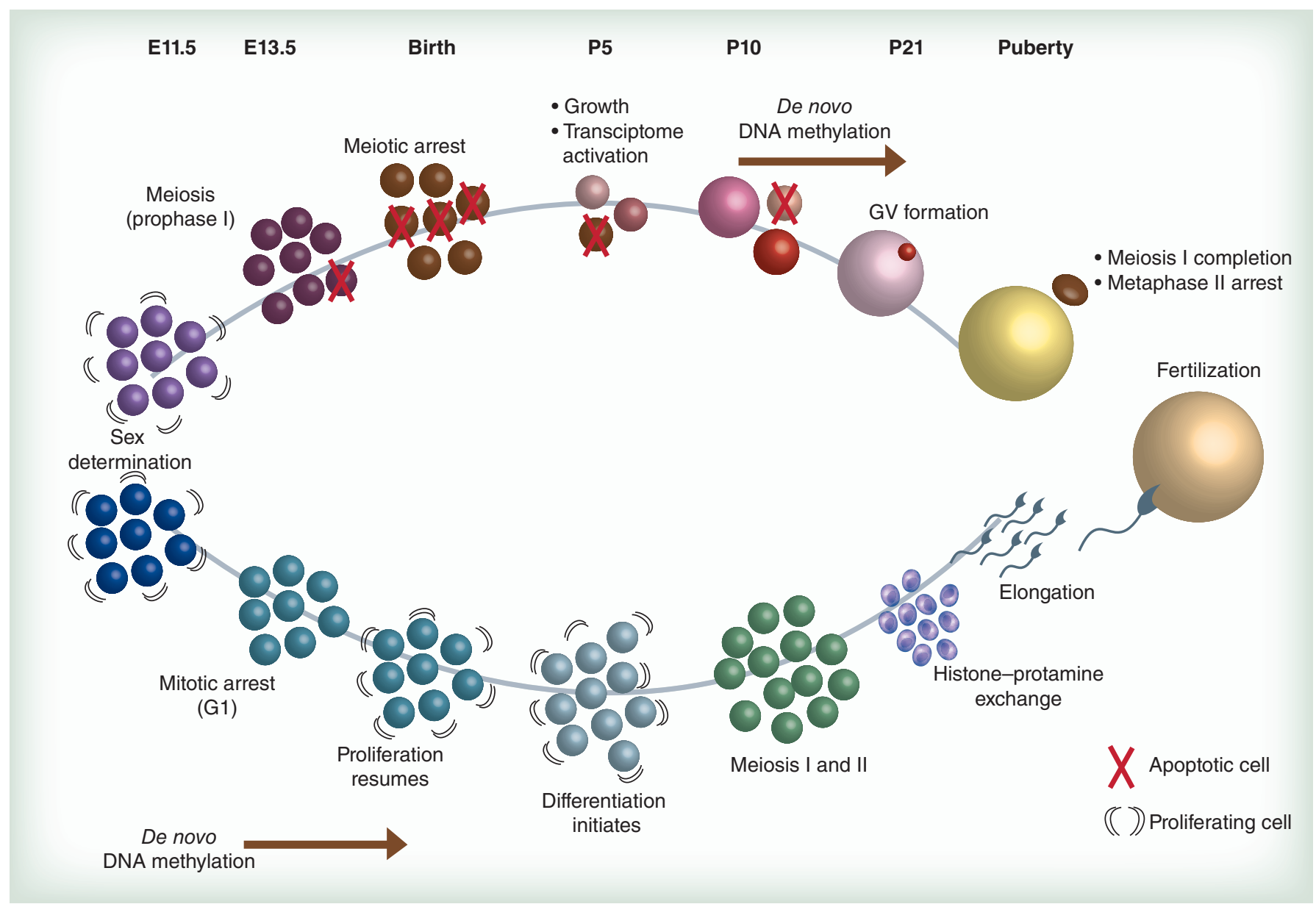

Figure 2. Nuclear and epigenetic dynamics in gametogenesis: temporal and developmental perspectives. In mice, sex determination occurs in the gonadal ridge between E10.5 and E12.5. At E13.5, primordial germ cells (PGCs) in both male and female developing gonads stop proliferating: female PGCs enter meiosis, while male PGCs (called prospermatogonia or gonocytes) arrest in mitotic G1 and undergo de novo DNA methylation between E13.5 and birth. By birth (approximately 19 days after conception), female PGCs have become primary oocytes, and arrest at the diplotene stage of meiotic prophase I. Many oocytes undergo apoptosis at this time, and oocytes continue to die throughout oogenesis. Male gametes, now spermatogonia, resume proliferation. At P5, oocytes begin expanding their cytoplasmic volume, and oocyte-specific transcription units also become active. This oocyte growth is asynchronous, with some oocytes growing faster than others. Spermatogonia begin to differentiate. De novo methylation begins in oocytes at around P10, or when an oocyte reaches at least 40-45 $\mu \mathrm{m}$ in diameter. Spermatogonia undergo meiosis at this time. Histoneprotamine exchange occurs in round spermatids at P21, which later elongate into mature spermatids. At P21, the oocyte methylome is established, and GVs form. Upon ovulation, oocytes become developmentally competent by completing meiosis I and arresting in metaphase II, while extruding the first polar body.

GV: Germinal vesicle.

of transposable elements in male germline, as well as of Rasgfrl, a paternally imprinted locus that contains a retrotransposon sequence in its gDMR [37]. The interplay between the piRNA pathway and the DNA methyltransferase enzymes remains incompletely understood, however, piRNAs appear to act upstream of DNMT3L, as loss of DNMT3L does not affect piRNA expression, while piRNA deficiency leads to loss of methylation at transposable elements [38,39].

Before genome-wide studies were possible, the mechanisms underlying DNA methylation in the germlines were poorly understood. However, maternally imprinted gDMRs presented a potentially more interesting context for studying de novo methylation, since there are more maternally imprinted than paternally imprinted gDMRs, and maternally imprinted gDMRs are also CGIs, a genomic feature mostly unmethylated in mammalian genomes. Several lines of evidence had suggested that transcription might be a common requirement for methylation establishment at maternally imprinted gDMRs. This was first functionally demonstrated for the complex imprinted locus Gnas, where interrupting transcription from an upstream oocyte-specific promoter led to loss of methylation at the downstream maternally imprinted gDMR [40,41]. Similar results were subsequently 
obtained for the gDMRs of the Snrpn and Zac1 imprinted loci $[42,43]$.

More recently, genome-wide methylation analyses have provided a holistic view of the sperm and oocyte methylomes. Genetic studies have revealed DNA methylation establishment in both oocytes and sperm is primarily due to the activity of DNMT3A and its cofactor DNMT3L [44-46]. DNMT3B is required for methylation at the Rasgrf1 imprinted gDMR and at satellites in sperm [33], but is dispensable for sperm production, and plays no role in the oocyte methylome [47].

Despite being established by the same DNMT3A/ DNMT3L complex, the sperm methylome is very different from the oocyte methylome: around $90 \%$ of CpGs are methylated in sperm, compared with $40 \%$ in oocytes $[29,48]$. Additionally, the distribution of DNA methylation differs greatly between oocytes and sperm: the oocyte methylome is characterized by striking alternating hypermethylated and hypomethylated domains, while in sperm DNA methylation is distributed more or less evenly throughout the genome, with the notable exception of CGIs (Figure 1). In support of a more general role for transcription in de novo DNA methylation in oocytes, hypermethylated and hypomethylated domains are respectively correlated with active transcription units, and intergenic or inactive genomic regions $[29,43]$. In sperm, both genic and intergenic regions gain methylation (Figure 1) $[29,48,49]$. Therefore, it appears that DNA methylation targeting by transcription is a particular feature of the female germline, while methylation is established more indiscriminately in the male germline. Nevertheless, this apparently indiscriminate methylation establishment might also be associated with transcription, as low-level genomewide transcription has been detected in prospermatogonia preceding DNA methylation establishment, including across paternally imprinted gDMRs [49]. The functional significance of transcription in patterning the sperm methylome has not yet been tested.

To precisely quantitate the correlation between transcription and DNA methylation in oocytes, we recently comprehensively mapped oocyte transcription units [43]. A number of oocyte-specific transcripts that traversed maternally imprinted gDMRs had already been described, and we therefore expected that the oocyte transcriptome would include many additional oocyte-specific transcripts not found in the mouse reference transcriptome. We identified approximately 9000 novel transcription units, some with proteincoding potential, and novel upstream promoters for almost 2000 annotated genes. This demonstrates that expression in the oocyte is uniquely regulated, and the functional consequences of this unique regulation may not be limited to DNA methylation establish- ment. Using the oocyte transcriptome, approximately $90 \%$ of the hypermethylated domains in the oocyte genome were correlated with transcription and, similarly, approximately $90 \%$ of hypomethylated domains were confirmed as untranscribed [43]. Though exceptions remain, this work demonstrates an exquisite correlation between transcription and DNA methylation in oocytes.

\section{Histone modifications \& DNA methylation establishment \\ DNA methylation correlates with histone modifications}

DNA methylation is known to correlate and anticorrelate with a number of different histone modifications. It is perhaps best-studied in relation to histone lysine methylation, a regulatory mark that recruits or repels chromatin-associated proteins via specific reader domains [50]. Through exclusion of the DNA methyltransferase complex, methylated histone $\mathrm{H} 3$ lysine 4 (H3K4) protects associated DNA from DNA methylation [51-53]. Both tri- and dimethyl $\mathrm{H} 3 \mathrm{~K} 4$ are classic marks of active promoters and CGIs [20,54] and, as a result, these regions usually lack DNA methylation. Histone $\mathrm{H} 3$ lysine 36 trimethylation $(\mathrm{H} 3 \mathrm{~K} 36 \mathrm{me} 3)$ is also associated with transcriptionally active chromatin, and is laid down in gene bodies by factors associated with the elongating RNApolII complex [55,56]. Unlike $\mathrm{H} 3 \mathrm{~K} 4 \mathrm{me} 2$ and $\mathrm{H} 3 \mathrm{~K} 4 \mathrm{me}$, H3K36me3 positively correlates with DNA methylation, and in most mammalian cells gene bodies are marked by both H3K36me3 and DNA methylation [57]. Additionally, DNA methylation and histone $\mathrm{H} 3$ lysine 9 (H3K9) methylation co-occur at heterochromatic regions. The relationship between DNA methylation and histone lysine methylation is well-documented in many cell contexts and has been reviewed elsewhere [58,59].

\section{Histone modifications can direct de novo DNA methylation}

In systems that begin with little or no DNA methylation, such as male and female PGCs, the histone modification landscape may influence DNA methylation by directing the DNA methyltransferase machinery $[59,60]$. Most work addressing the roles of histone modifications in DNA methylation establishment has been done in systems that have been manipulated to lack DNA methylation, such as mouse embryonic stem cells (mESCs) that lack the methyltransferases DNMT3A, DNMT3B and DNMT1 [61]. This system has been used to interrogate DNMT3A and DNMT3B recruitment to chromatin using rescue experiments that reintroduce one or both methyltransferases. Using such a system, Baubec et al. recently demonstrated 
that H3K36me3-marked regions gain DNA methylation when DNMT3A and, particularly, DNMT3B are reintroduced [62]. When murine DNMT3B is introduced in yeast, which lack endogenous DNA methylation, it similarly methylates $\mathrm{H} 3 \mathrm{~K} 36 \mathrm{me} 3$-associated DNA [63]. H3K36me3 can recruit DNMT3A via its PWWP domain in vitro [64], and in the mouse oocyte DNMT3A is the only active methyltransferase [47], suggesting that in the absence of DNMT3B it could be recruited to H3K36me3-marked DNA and establish DNA methylation. Recruitment of the DNMT3A/DNMT3L methyltransferase complex by $\mathrm{H} 3 \mathrm{~K} 36 \mathrm{me} 3$ could therefore be the mechanism underlying the tight correlation observed between transcription and DNA methylation in oocytes.

Recruitment of DNMT3A and DNMT3B to chromatin has been extensively studied in vitro, but the de novo DNA methylation that occurs in vivo during gametogenesis and early embryogenesis can further inform our understanding of how histone modifications and DNA methylation influence one another. In developing and mature sperm, which have been profiled using both whole-genome bisulfite sequencing and ChIP-Seq methods, H3K4me2- and H3K4me3-marked regions remain unmethylated, while the majority of other $\mathrm{CpG}$ dinucleotides gain methylation $[48,49]$. This pattern of DNA methylation is seen in somatic cells, but seeing the same result in sperm provides stronger evidence that histone modifications pattern de novo DNA methylation, since in prospermatogonia DNA methylation establishment takes place on a largely unmethylated genome. Notably, $99 \%$ of histones in mature mouse sperm are exchanged for protamines - small, arginine-rich proteins which allow DNA to condense more than canonical nucleosomes (Figure 2) [65]. Retained histones are disproportionately found at CGIs and are characterized by $\mathrm{H} 3 \mathrm{~K} 4 \mathrm{me} 2$ and $\mathrm{H} 3 \mathrm{~K} 4 \mathrm{me} 3$, suggesting that histones may be retained at these loci specifically to prevent de novo methylation $[48,66,67]$.

It is now well-established that $\mathrm{H} 3 \mathrm{~K} 4 \mathrm{me} 2$ and H3K4me3 protect associated DNA from DNA methylation, and that this inhibition protects most CGIs and transcriptional start sites from aberrantly acquiring DNA methylation [68]. To establish DNA methylation at a CGI, such as a maternally imprinted DMR, H3K4me2 and H3K4me3 therefore would first have to be removed. Single-gene analyses of oocytes from mice deficient in the H3K4me2 demethylase KDM1B have shown that several maternally imprinted gDMRs fail to gain methylation in the absence of this enzyme [69]. This suggests that $\mathrm{H} 3 \mathrm{~K} 4 \mathrm{me} 2$ is aberrantly retained at the maternally imprinted gDMRs that are unmethylated in the absence of KDM1B. Most CGIs that gain methylation in the oocyte, both imprinted and non- imprinted, are found within active transcription units, suggesting they are enriched for H3K36me3. Unlike sperm, oocytes are difficult to isolate in the numbers required for standard ChIP-Seq, so although wholegenome bisulfite sequencing of oocytes has now been done by several groups, comparing the oocyte methylome to the histone modification landscapes in oocytes was not previously possible.

We recently interrogated the mechanistic links between histone modifications and transcription in oocytes using two different approaches. Disrupting transcription at the imprinted $Z a c 1$ locus through genetic deletion of the oocyte-specific Zaclo promoter led to loss of DNA methylation throughout the locus, which was accompanied by loss of H3K36me3 in the $\mathrm{Zacl}$ gene body and retention of $\mathrm{H} 3 \mathrm{~K} 4 \mathrm{me} 2$ at the $\mathrm{Zacl}$ imprinted gDMR [43]. This demonstrated a functional requirement for transcription in DNA methylation establishment. It also showed that in the absence of transcription CGI chromatin is not remodeled, and the histone modification landscape at a CGI that normally gains DNA methylation in oocytes remains incompatible with DNA methylation establishment. Genomewide methylation profiling in oocytes lacking KDM1B revealed widespread loss of methylation in gene bodies and imprinted gDMRs, including the Zac1 gDMR [70] . RNA-seq revealed that transcription is largely normal in KDM1B-deficient oocytes, indicating KDM1B acts downstream of transcription.

Although the majority of measurable CGIs were hypomethylated in KDM1B-knockout oocytes compared with wild-type, a subset of CGIs fully gained methylation in the knockout oocytes, indicating KDM1B is not universally required for CGI methylation. Using novel techniques for oocyte isolation and low-cell ChlP-Seq, we noted that CGIs sensitive to KDM1B had higher H3K4me2 levels in wild-type oocytes than other CGIs, which suggests that the demethylase activity of KDM1B is required at these loci for proper establishment of DNA methylation [70]. To confirm this correlation between higher $\mathrm{H} 3 \mathrm{~K} 4 \mathrm{me} 2$ levels and a requirement for KDM1B, future experiments should include ChIP-seq in KDM1B-knockout oocytes. We also observed an increase between the primary and growing oocyte stages in $\mathrm{H} 3 \mathrm{~K} 36 \mathrm{me} 3$ at CGIs destined for DNA methylation (Figure 3), suggesting this is a general mechanism that specifies these loci for subsequent methylation [70].

Recently, Nashun et al. reported widespread hypomethylation in oocytes deficient in the $\mathrm{H} 3.3$ chaperone HIRA [71]. HIRA deposits H3.3 in a replication-independent manner at euchromatin [72], and in the nondividing mouse oocyte deleting HIRA caused reduced histone load genome-wide [71]. HIRA-knockout 


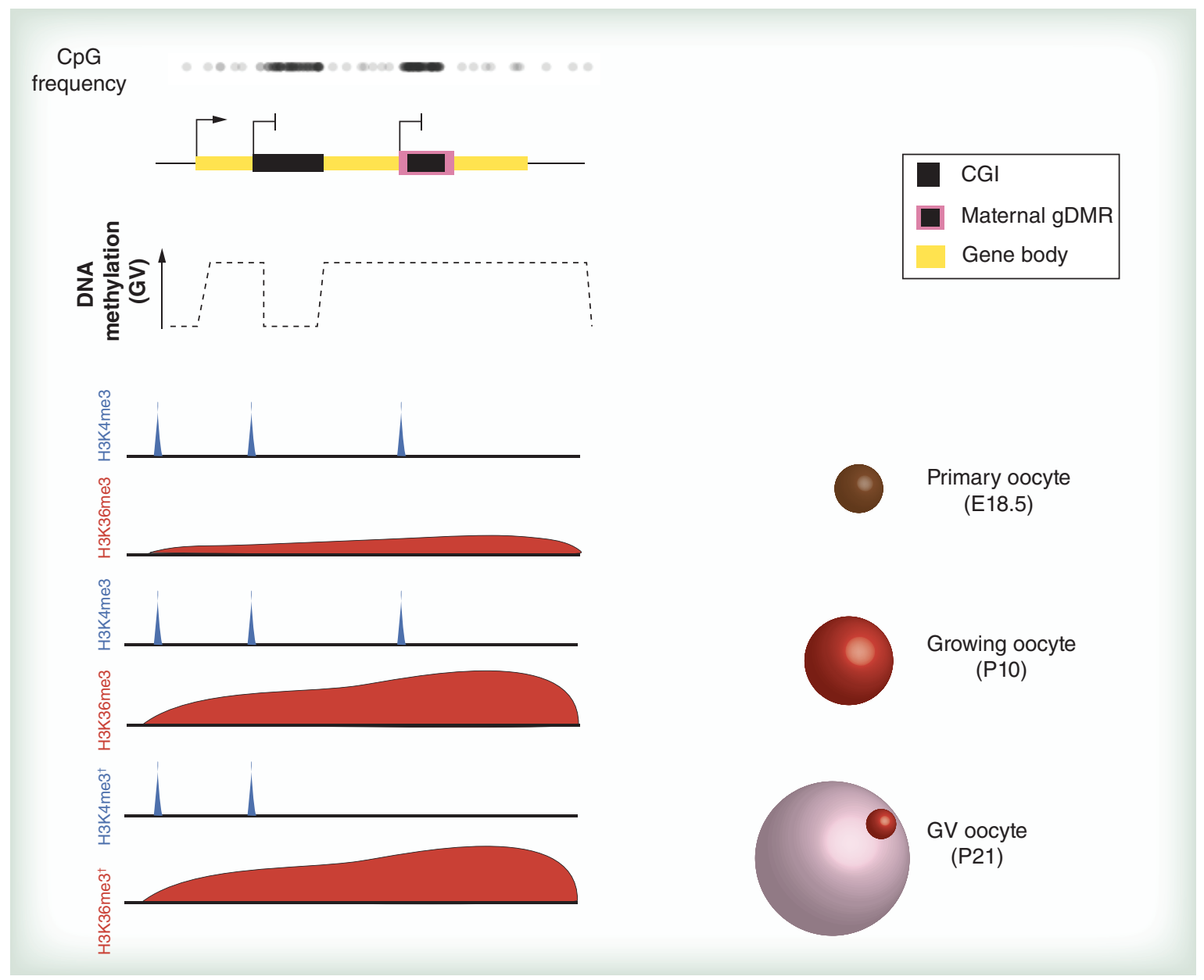

Figure 3. Chromatin modulation accompanies establishment of the oocyte DNA methylome. CGIs and maternally imprinted gDMRs that gain methylation in the oocyte tend to be within active transcription units, but not all transcribed CGIs acquire DNA methylation (top). In the scheme shown, the yellow bar at the top represents a single transcription unit that contains two intragenic CGIs that are initially both marked with H3K4me3 in primary oocytes at E18.5 (these CGIs may be active promoters in other cell types). In growing (P10) oocytes, most CGIs destined for DNA methylation retain this $\mathrm{H} 3 \mathrm{~K} 4 \mathrm{me} 3$ and, compared with CGIs that resist DNA methylation, they also become enriched in $\mathrm{H} 3 \mathrm{~K} 36 \mathrm{me} 3$. Presumed loss of H3K4me3 sometime between $\mathrm{P} 10$ and $\mathrm{P} 21$ then permits DNA methylation establishment at these loci by the GV oocyte stage.

${ }^{\dagger}$ Hypothesized profiles.

CGI: CpG island; gDMR: Germline differentially methylated region; GV: Germinal vesicle.

oocytes showed DNA hypomethylation even in regions that were transcribed normally, indicating that the requirement for a specific histone modification profile in de novo DNA methylation is subordinate to a general requirement for intact nucleosomes. This makes sense, given structural and biochemical data that show the DNMT3A/DNMT3L complex is activated through interaction with the histone $\mathrm{H} 3$ tail $[73,74]$.

Taken together, these results indicate that in oocytes transcription facilitates establishment of chromatin states that permit DNA methylation, especially at CGIs that are normally marked with inhibitory H3K4 methylation [43,70]. However, this chromatin remodeling may not be achieved through a single histone modifier, as evidenced by the subset of oocyte- methylated CGIs that gain normal DNA methylation levels in the absence of KDM1B. Although the mature oocyte methylome is highly stereotypical, the histone modification landscape in these methylated domains is not uniform prior to de novo methylation [70]. As a consequence of this, it is likely that a different balance of factors, including different histone modifiers, is required at different genomic locations to render the DNA in these regions susceptible to DNA methylation. For example, CpG-dense CGIs, which have high $\mathrm{H} 3 \mathrm{~K} 4 \mathrm{me} 2$ and $\mathrm{H} 3 \mathrm{~K} 4 \mathrm{me} 3$, may require active removal of this mark prior to methylation establishment (Figure 3), while at CpG-poor CGIs deposition of H3K36me3 alone may be sufficient to target DNA methylation. 


\section{Unanswered questions in DNA methylation establishment}

The link between transcription-associated histone modifications and DNA methyltransferase recruitment can, at least in theory, largely explain the oocyte methylation landscape. However, it also raises the question of why the DNMTs, specifically DNMT3A and DNMT3B, seem preferentially to target genomic features in a cell type-specific manner. In mESCs, where both DNMT3A and DNMT3B are present, it is DNMT3B, not DNMT3A, that preferentially methylates genic regions [62]. DNMT3A and DNMT3B have virtually identical PWWP domains, which both bind to H3K36me3 [64,75]. It is therefore unclear why this preferential targeting of DNMT3B would occur when both enzymes are present, as is the case in mESCs. It could be evidence for DNMT3B being more important generally in an embryonic context; DNMT3B knockout mice die mid-gestation, while DNMT3A knockout mice die much later, at around weaning [45]. Also unclear are the mechanisms underlying the very different methylomes seen in mature oocytes and sperm. Why would DNMT3A/3L be so precisely targeted to genic regions in the oocyte, but be so indiscriminate in sperm? Adding another layer of complexity, recent profiling of the human oocyte methylome shows the same genic/intergenic patterning of hypermethylated and hypomethylated domains seen in mouse [76], yet human oocytes lack DNMT3L [77]. This suggests that the oocyte methylome is determined through DNMT3A targeting alone, or that it is a consequence of some as-yet unidentified aspect of oocyte biology.

De novo methylation occurs prior to histone-protamine exchange in spermatogenesis, so in theory post-translational histone modifications could direct methylation in this context, but there is no clear correlation between any such modification and the genomewide methylation seen in sperm. Instead, the sperm methylome is generally similar to the methylomes of somatic cells, in which $>70 \%$ of $\mathrm{CpG}$ dinucleotides are methylated. But it is important to note that sequenceindependent methylation establishment in both the male and female germlines allows for the epigenetic plasticity that underlies sex-specific de novo methylation of imprinted gDMRs, and evolutionarily creates the opportunity for new imprinted gDMRs to arise.

\section{Roles of DNA methylation in sperm \& oocytes}

DNA methylation is essential for the correct development of the male germline. DNMT3A or DNMT3L deficiency leads to meiotic failure, apoptotic loss of spermatocytes and sterility. This is presumably due to the downregulation of germ cell-specific genes and transcriptional activation of transposable elements that become capable of retrotransposition [46,78-80]. These phenotypes are accompanied by genome-wide hypomethylation. DNA methylation in the male germline has also recently been shown to play a role in preventing retrotransposons from participating in meiotic recombination [81].

Though the oocyte has many unique epigenetic features, the most perplexing may be its unique methylome. Unlike the methylome of any other differentiated mammalian cell, the oocyte methylome is predominantly genic, with almost no methylation in intergenic regions. This patterning bears a strong resemblance to invertebrate methylomes, and is therefore probably very ancient [82]. Why has the oocyte retained this distribution of CpG methylation, when no other mammalian cell analyzed thus far has? Unfortunately, the functional role of methylation in the oocyte is not very informative in this regard; oocytes can mature, progress through meiosis and become fertilized in the absence of DNA methylation [8,78,83]. Thus far, the only definitive roles for oocyte DNA methylation are in post-fertilization contexts. Although DNMT3Aand DNMT3L-deficient oocytes can be fertilized normally, embryos conceived from these oocytes die by E10.5 [78], largely because of the absence of methylation at maternally imprinted gDMRs.

Apart from imprinted gDMRs, the majority of methylation marks established in gametes are erased after fertilization. Nevertheless, some regions other than imprinted gDMRs maintain gametic methylation post-fertilization $[28,29,84]$. In the majority of cases, these regions retain methylation from oocytes on the maternally inherited allele, while the paternal allele gains methylation during postimplantation development $[21,85-87]$. These observations have given rise to the concept of transient DMRs [86]. It remains unclear whether nonimprinted, oocyte-derived methylation has any major function during embryonic development, however, two recent studies revealed that at some loci, this methylation plays a role in transcriptional regulation in the embryo [87,88]. More recently, maternal methylation has also been shown to be required in extra-embryonic tissue, specifically in trophoblast. Conceptuses from DNMT3A-deficient oocytes, which lack DNA methylation, exhibited misregulated transcription and developmental defects in trophoblast cells [89]. Advances in genome-wide analyses of rare cells may reveal further roles for maternally derived methylation in early development.

The oocyte's ability to progress normally through oogenesis in the absence of DNA methylation suggests it employs alternative mechanisms to regulate gene expression and repress repetitive elements. Oocytes lacking the nucleosome remodeler LSH exhibit meiotic 
defects, hypomethylation of repeat elements and retrotransposon reactivation, echoing the phenotype seen in DNMT3L-deficient spermatocytes [90]. Throughout oogenesis, oocytes are heavily reliant on extracellular signaling from other cells within the follicle including to initiate translation of mRNAs related to meiotic progression and developmental competence [91]. This extreme dependence on noncell-autonomous mechanisms of gene regulation may explain the oocyte's ability to tolerate a lack of DNA methylation, and represents a unique system of transcriptional regulation among mammalian cells.

\section{Fate of gametic DNA methylation after fertilization}

The maternal and paternal pronuclei are differentially marked with both DNA methylation and histone modifications in the early zygote. The paternal pronucleus is largely devoid of histones and is heavily DNA-methylated, while the maternal pronucleus is organized around canonical histones bearing post-translational modifications and is DNA-methylated primarily in genic regions. After fertilization, the paternal pronucleus is extensively remodeled in a process that entails active DNA demethylation [92,93] and protamine-histone exchange characterized by deposition of maternal H3.3 (Figure 4) [94,95]. The maternal pronucleus largely resists this initial wave of demethylation, although it has recently been shown that the maternal genome is subject to both de novo methylation and hydroxylation in the zygote [96]. Instead, through failure to maintain
DNA methylation following DNA replication, the maternal genome passively loses methylation in successive cell divisions. Following implantation, DNA methylation is re-established in the embryonic and extra-embryonic lineages, through processes that have been reviewed elsewhere [97].

\section{Gametic methylation \& transgenerational inheritance}

There has been much speculation about the possibility of transgenerational epigenetic inheritance in mammals [98]. Studies of transgenerational epigenetic inheritance mostly focus on paternal inheritance, as this avoids confounding in utero effects and other maternal influences that complicate studies of maternal inheritance. It has been shown by multiple groups that the sperm methylome can be perturbed by environmental influences [99-101]. However, Shea et al. demonstrated recently that sibling mice that were fed different diets had more similar sperm methylomes than nonsiblings on identical diets, demonstrating that naturally occurring epigenetic variation influences the sperm methylome more than paternal diet [102]. DNA methylation changes in sperm may therefore not have a direct effect on offspring.

It is thought that diffusible factors from the gametes, such as RNAs, may in general be a greater source of transgenerational epigenetic information than DNA methylation [103]. A recent study demonstrating that tRNA composition in sperm is affected by paternal diet, and that these tRNA fragments can regulate genes that are highly expressed in the preimplantation

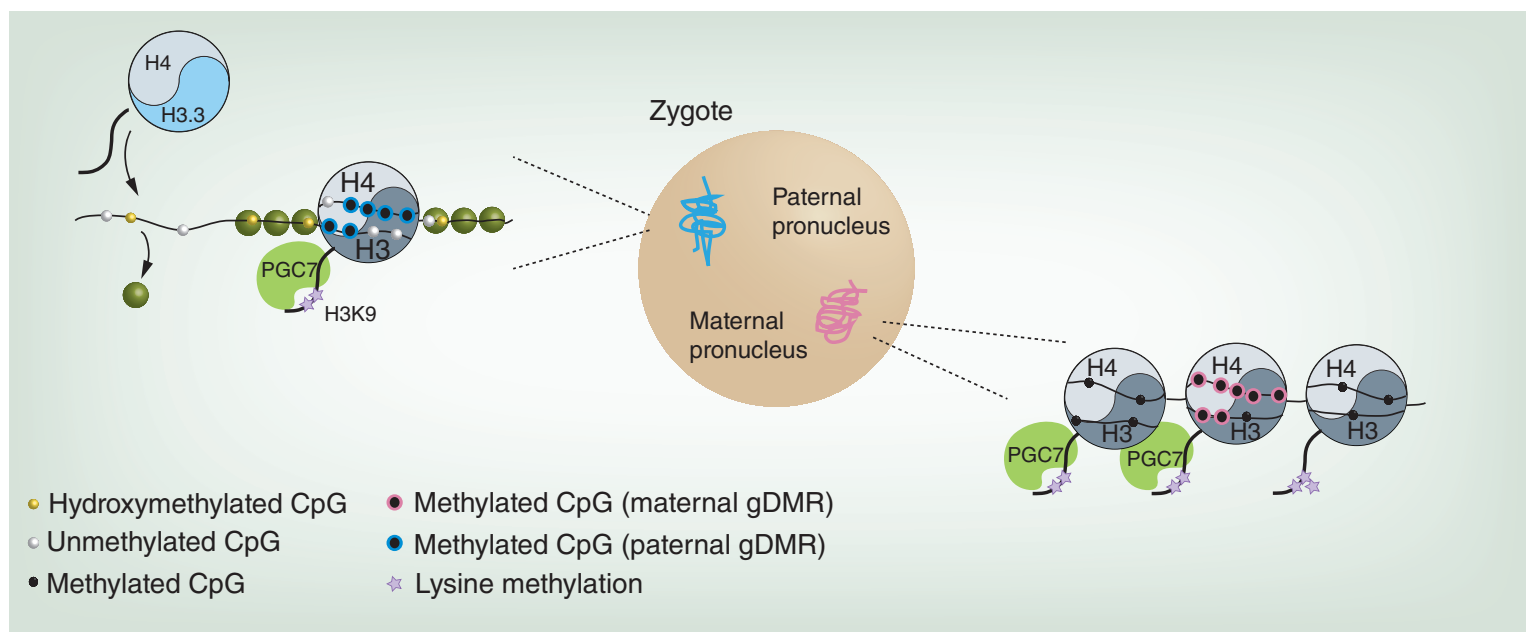

Figure 4. Gametic epigenomes in the zygote. Following fertilization, most of the paternal genome is actively demethylated, during which time it is characterized by widespread hydroxymethylation. The few canonical nucleosomes present in mature sperm are predicted to persist in the paternal pronucleus, but in the majority of the genome protamines (green circles) are exchanged for maternally provided histones containing the $\mathrm{H} 3$ variant H3.3. The maternal genome is largely not subject to either of these remodeling events. Nucleosomes marked with H3K9me2 recruit PGC7/STELLA, which protects the maternal genome from demethylation. The same mechanism protects DNA methylation over at least two paternally imprinted gDMRs.

gDMR: Germline differentially methylated region; PGC: Primordial germ cell. 
embryo, provides an alternative plausible mechanism for paternal transgenerational influence [104]. Nonetheless, some genomic loci, in particular intracisternal A particles, fail to become completely demethylated prior to de novo methylation in PGCs, providing a potential source of transgenerational information via DNA methylation [31,105], and the consequences of such retained methylation remain to be uncovered.

\section{Histone modifications underlie asymmetric DNA methylation in the zygote}

The gametes do not only contribute their unique methylomes to the zygote; the epigenetic information contained in modified histones is also transmitted at fertilization. Sperm, oocytes, zygotes and the early embryo have been extensively studied using immunofluorescence and genetic methods, which have provided insights into the histone modifications that characterize these cells. Several lines of evidence suggest that, as in DNA methylation establishment, histone modifications may influence DNA methylation retention and loss in the zygote (Figure 4).

De novo DNA methylation is directed by the distributions of active histone marks in the gametes: H3K4me2 and H3K4me3 in sperm; and H3K4me2, H3K4me3 and $\mathrm{H} 3 \mathrm{~K} 36 \mathrm{me} 3$ in oocytes. DNA methylation retention in the zygote, conversely, is reliant on co-occurrence of DNA methylation and heterochromatic marks: $\mathrm{H} 3 \mathrm{~K} 9 \mathrm{me} 2, \mathrm{H} 3 \mathrm{~K} 9 \mathrm{me} 3$ and histone $\mathrm{H} 3$ lysine 27 trimethylation (H3K27me3). PGC7/STELLA is a maternal factor that binds $\mathrm{H} 3 \mathrm{~K} 9 \mathrm{me} 2$ and is required to protect the maternal pronucleus from DNA demethylation (Figure 4) [106,107]. Reducing H3K9me2 levels causes loss of PGC7/STELLA binding and loss of methylation in the maternal pronucleus, indicating that in wild-type zygotes it is the absence of $\mathrm{H} 3 \mathrm{~K} 9 \mathrm{me} 2$ that renders the paternal genome vulnerable to DNA demethylation. Further, two of the three paternally imprinted gDMRs are marked with $\mathrm{H} 3 \mathrm{~K} 9 \mathrm{me} 2$ in sperm and are hypomethylated in PCG7-knockout embryos, suggesting the PCG7/STELLA interaction with $\mathrm{H} 3 \mathrm{~K} 9 \mathrm{me} 2$ is a general mechanism for DNA methylation retention in the zygote [107]. Polycomb group factors are specifically required to maintain imprinted gene expression in the embryo, suggesting H3K27me3, which is deposited by the Polycomb group component EZH2, is also present on imprinted gDMRs in the zygote $[108,109]$.

\section{DNA methylation \& histone modifications in the early embryo}

Both maternally and paternally imprinted gDMRs retain monoallelic methylation in the zygote, early embryo and postimplantation [13]. Maternally derived, nonimprinted methylation is mostly removed by the morula stage but, intriguingly, the extra-embryonic lineages are characterized by a gene body methylation signature reminiscent of the oocyte methylome [110]. Additionally, there exist several placenta-specific imprinted genes that lack promoter DNA methylation; these loci are instead monoallelically marked with repressive $\mathrm{H} 3 \mathrm{~K} 27 \mathrm{me} 3$, H3K9me2 and $\mathrm{H} 3 \mathrm{~K} 9 \mathrm{me} 3$ methylation [111-113]. However, there is no evidence yet that such repressive modifications were present at these loci in oocytes and they could equally depend on oocyte-derived DNA methylation at the corresponding imprinting control region.

While the maternal genome is decorated with $\mathrm{H} 3 \mathrm{~K} 9 \mathrm{me} 3$ and $\mathrm{H} 3 \mathrm{~K} 27 \mathrm{me} 3$ in germinal vesicle oocytes, the paternal genome loses these marks during spermatogenesis $[114,115]$. The asymmetry in $\mathrm{H} 3 \mathrm{~K} 9 \mathrm{me} 3$ methylation between the maternal and paternal genomes persists in the first cell divisions of embryonic development, while both pronuclei are marked with H3K27me3 by the end of the 1-cell stage [116]. There are intriguing parallels between the retention of $\mathrm{H} 3 \mathrm{~K} 9$ methylated histones and protection from active DNA demethylation in the maternal genome (Figure 4), possibly explaining the oocyte-like methylome seen in preimplantation embryos and early extra-embryonic tissues [84,110].

\section{Future perspective}

Descriptive studies of DNA methylation in the gametes and early embryo have provided many new avenues for research, but the function of this methylation, especially of maternally derived methylation, is in many cases still unclear. The striking methylome and modes of transcriptional regulation in the mouse oocyte make it unique from epigenetic, cell signaling and evolutionary perspectives. Additionally, even in the postgenomics era the paradigm of genomic imprinting has remained an invaluable model of epigenetic regulation, and will likely continue to be so [15].

Although the histone modifications that characterize the maternal and paternal genomes have been studied extensively by immunofluorescence, it remains largely unknown whether or not these modifications are directly inherited by or play a role in the early embryo. With the rapid advances in chromatin profiling of rare cell populations, the precise localization of histone marks in the mature oocyte and early embryo will likely soon be known. It is likely that the roles of both gamete-derived and newly deposited histones in the zygote will be complex and multifaceted. This is demonstrably the case for DNA methylation, which appears to be much more dynamic within the zygote than was previously appreciated [96]. And though DNA methylation is seemingly less instructive in transgenerational inheritance than 
initially speculated, the roles of histone modifications and inherited RNA molecules remain exciting potential transmitters of epigenetic information between generations that deserve further investigation.

The mouse is a powerful model for studying DNA methylation establishment in vivo. Rapid advances in next-generation sequencing technologies, especially those adapted to single cells or low cell numbers, are revealing the complex interplay between DNA methylation, histone modifications and other epigenetic factors during gametogenesis and early mouse development. These developments have also initiated the advent of parallel analyses in human oocytes and early embryos, revealing important similarities and differences between mouse and human $[76,117,118]$. These studies will continue to expand our understanding of mammalian development, and will also shed light on how well murine gametogenesis and embryogenesis model these processes in human.
Financial \& competing interests disclosure

KR Stewart was supported by a studentship from the Cambridge Overseas Trusts. L Veselovska was supported by a Babraham Institute: Cambridge University studentship. Work in G Kelsey's laboratory is funded by the Biotechnology and Biological Sciences Research Council and the Medical Research Council. The authors have no other relevant affiliations or financial involvement with any organization or entity with a financial interest in or financial conflict with the subject matter or materials discussed in the manuscript apart from those disclosed.

No writing assistance was utilized in the production of this manuscript.

\section{Open access}

This work is licensed under the Creative Commons Attribution 4.0 License. To view a copy of this license, visit http:// creativecommons.org/licenses/by/4.0

\section{Executive summary}

\section{DNA methylation establishment in gametes}

- Starting from essentially unmethylated genomes in primordial germ cells, gametogenesis results in distinctive DNA methylation landscapes in mature oocytes and sperm.

- In oocytes, DNA methylation is overwhelmingly associated with gene bodies, and transcription has been functionally demonstrated to determine methylated domains, including the differentially methylated regions of imprinted genes.

- In the male germline, DNMT3B has a specific role in methylation of transposable elements associated with piRNAs, although the underlying mechanism is unresolved.

- It is not understood why the methylomes of oocyte and sperm are strikingly different, since in mouse both depend mainly on DNMT3A and DNMT3L.

Histone modifications \& DNA methylation establishment

- Germ cells provide important in vivo systems to interrogate the relationship between histone post-translational modifications and de novo DNA methylation.

- In oocytes, transcription may lead to recruitment of DNMT3A via transcription-coupled deposition of H3K36me3, analogous to the targeting of DNMT3B observed in embryonic stem cells but indicating cell-specific effects.

- In oocytes, transcription is involved in removing H3K4 methylation at imprinted differentially methylated regions, which is inhibitory to DNA methylation.

- Deleting the H3K4me2 demethylase KDM1B does not equally affect CpG islands destined for methylation in oocytes, suggesting different loci require different combinations of factors to render them susceptible to DNA methylation.

Roles of DNA methylation in sperm \& oocytes \& its fate in the embryo

- Spermatogenesis fails in the absence of DNA methylation, but oocytes can develop normally.

- Despite extensive active and passive demethylation in the zygote and cleavage-stage embryo, sites of oocyte-derived methylation outside imprinted genes are retained and are essential for development, particularly of the placenta.

- The contribution of DNA methylation abnormalities to transgenerational epigenetic inheritance remains contentious and requires further investigation.

DNA methylation \& histone modifications in the early embryo

- There is extensive asymmetry of histone modifications between the parental genomes at fertilization and in their dynamics after fertilization.

- The co-occurrence of repressive histone modifications, such as $\mathrm{H} 3 \mathrm{~K} 9 \mathrm{me} 2$ and $\mathrm{H} 3 \mathrm{~K} 9 \mathrm{me}$, may be required to protect imprinted differentially methylated regions and other sequence elements against demethylation in the zygote and early embryo.

- Sophisticated genetic studies, as well as advances in low-cell ChIP-seq, will be required to elucidate fully the relationships between gamete-derived DNA methylation and histone modifications in the early embryo. 


\section{References}

Papers of special note have been highlighted as:

- of interest; $\bullet \bullet$ of considerable interest

1 Jones PA. Functions of DNA methylation: islands, start sites, gene bodies and beyond. Nat. Rev. Genet. 13(7), 484-492 (2012).

2 Chen T, Li E. Structure and function of eukaryotic DNA methyltransferases. Curr. Top. Dev. Biol. 60, 55-89 (2004).

3 Hitt MM, Wu TL, Cohen G, Linn S. De novo and maintenance DNA methylation by a mouse plasmacytoma cell DNA methyltransferase. J. Biol. Chem. 263(9), 4392-4399 (1988).

4 Pradhan S, Bacolla A, Wells RD, Roberts RJ. Recombinant human DNA (cytosine-5) methyltransferase: I. Expression, purification, and comparison of de novo and maintenance methylation. J. Biol. Chem. 274(46), 33002-33010 (1999).

5 Arita K, Ariyoshi M, Tochio H, Nakamura Y, Shirakawa M. Recognition of hemi-methylated DNA by the SRA protein UHRF1 by a base-flipping mechanism. Nature 455(7214), 818-821 (2008).

6 Avvakumov GV, Walker JR, Xue S et al. Structural basis for recognition of hemi-methylated DNA by the SRA domain of human UHRF1. Nature 455(7214), 822-825 (2008).

7 Okano M, Xie S, Li E. Cloning and characterization of a family of novel mammalian DNA (cytosine-5) methyltransferases. Nat. Genet. 19(3), 219-220 (1998).

8 Bourc'his D, Xu G-L, Lin C-S, Bollman B, Bestor TH. Dnmt3L and the establishment of maternal genomic imprints. Science 294(5551), 2536-2539 (2001).

9 Chédin F, Lieber MR, Hsieh C-L. The DNA methyltransferase-like protein DNMT3L stimulates de novo methylation by Dnmt3a. Proc. Natl Acad. Sci. USA 99(26), 16916-16921 (2002).

10 Gowher H, Liebert K, Hermann A, Xu G, Jeltsch A. Mechanism of stimulation of catalytic activity of Dnmt3A and Dnmt3B DNA-(cytosine-C5)-methyltransferases by Dnmt3L. J. Biol. Chem. 280(14), 13341-13348 (2005).

11 Jia D, Jurkowska RZ, Zhang X, Jeltsch A, Cheng X. Structure of Dnmt3a bound to Dnmt3L suggests a model for de novo DNA methylation. Nature 449(7159), 248-251 (2007).

12 Wienholz BL, Kareta MS, Moarefi AH, Gordon CA, Ginno PA, Chédin F. DNMT3L modulates significant and distinct flanking sequence preference for DNA methylation by DNMT3A and DNMT3B in vivo. PLoS Genet. 6(9), e1001106 (2010).

13 Hanna CW, Kelsey G. The specification of imprints in mammals. Heredity 113(2), 176-183 (2014).

14 Feil R, Berger F. Convergent evolution of genomic imprinting in plants and mammals. Trends Genet. 23(4), 192-199 (2007).

15 Ferguson-Smith AC. Genomic imprinting: the emergence of an epigenetic paradigm. Nat. Rev. Genet. 12(8), 565-575 (2011).

16 Wang L, Zhang J, Duan J et al. Programming and inheritance of parental DNA methylomes in mammals. Cell 157(4), 979-991 (2014).
17 Tomizawa S, Kobayashi H, Watanabe T et al. Dynamic stage-specific changes in imprinted differentially methylated regions during early mammalian development and prevalence of non-CpG methylation in oocytes. Development 138(5), 811-820 (2011).

18 Kobayashi H, Suda C, Abe T, Kohara Y, Ikemura T, Sasaki H. Bisulfite sequencing and dinucleotide content analysis of 15 imprinted mouse differentially methylated regions (DMRs): paternally methylated DMRs contain less CpGs than maternally methylated DMRs. Cytogenet. Genome Res. 113(1-4), 130-137 (2006).

19 Deaton AM, Bird A. CpG islands and the regulation of transcription. Genes Dev. 25(10), 1010-1022 (2011).

20 Illingworth RS, Gruenewald-Schneider U, Webb S et al. Orphan CpG islands identify numerous conserved promoters in the mammalian genome. PLoS Genet. 6(9), e1001134 (2010).

21 Auclair G, Guibert S, Bender A, Weber M. Ontogeny of $\mathrm{CpG}$ island methylation and specificity of DNMT3 methyltransferases during embryonic development in the mouse. Genome Biol. 15(12), 545 (2014).

22 Illingworth R, Kerr A, Desousa D et al. A novel CpG island set identifies tissue-specific methylation at developmental gene loci. PLoS Biol. 6(1), e22 (2008).

23 Maunakea AK, Nagarajan RP, Bilenky M et al. Conserved role of intragenic DNA methylation in regulating alternative promoters. Nature 466(7303), 253-257 (2010).

24 Lienert F, Wirbelauer C, Som I, Dean A, Mohn F, Schubeler D. Identification of genetic elements that autonomously determine DNA methylation states. Nat. Genet. 43(11), 1091-1097 (2011).

25 Wachter E, Quante T, Merusi C et al. Synthetic CpG islands reveal DNA sequence determinants of chromatin structure. eLife 3, e03397 (2014).

26 Krebs AR, Dessus-Babus S, Burger L, Schübeler D. Highthroughput engineering of a mammalian genome reveals building principles of methylation states at CG rich regions. eLife 3, e04094 (2014).

27 Marchal C, Miotto B. Emerging concept in DNA methylation: role of transcription factors in shaping DNA methylation patterns. J. Cell. Physiol. 230(4), 743-751 (2015).

28 Smallwood SA, Tomizawa S-I, Krueger F et al. Dynamic $\mathrm{CpG}$ island methylation landscape in oocytes and preimplantation embryos. Nat. Genet. 43(8), 811-814 (2011).

29 Kobayashi H, Sakurai T, Imai M et al. Contribution of intragenic DNA methylation in mouse gametic DNA methylomes to establish oocyte-specific heritable marks. PLoS Genet. 8(1), e1002440 (2012).

-• Reports the first whole-genome DNA methylation landscape of mammalian oocytes.

30 Guibert S, Forné T, Weber M. Global profiling of DNA methylation erasure in mouse primordial germ cells. Genome Res. 22(4), 633-641 (2012).

31 Seisenberger S, Andrews S, Krueger F et al. The dynamics of genome-wide DNA methylation reprogramming in mouse primordial germ cells. Mol. Cell 48(6), 849-862 (2012). 
32 Li J-Y, Lees-Murdock DJ, Xu G-L, Walsh CP. Timing of establishment of paternal methylation imprints in the mouse. Genomics 84(6), 952-960 (2004).

33 Kato Y, Kaneda M, Hata K et al. Role of the Dnmt3 family in de novo methylation of imprinted and repetitive sequences during male germ cell development in the mouse. Hum. Mol. Genet. 16(19), 2272-2280 (2007).

34 Hiura H, Obata Y, Komiyama J, Shirai M, Kono T. Oocyte growth-dependent progression of maternal imprinting in mice. Genes Cells 11(4), 353-361 (2006).

35 Lucifero D, Mann MRW, Bartolomei MS, Trasler JM. Gene-specific timing and epigenetic memory in oocyte imprinting. Hum. Mol. Genet. 13(8), 839-849 (2004).

36 Obata Y, Kono T. Maternal primary imprinting is established at a specific time for each gene throughout oocyte growth. J. Biol. Chem. 277(7), 5285-5289 (2002).

37 Watanabe T, Tomizawa S-I, Mitsuya K et al. Role for piRNAs and noncoding RNA in de novo DNA methylation of the imprinted mouse Rasgrf1 locus. Science 332(6031), 848-852 (2011).

38 Aravin AA, Sachidanandam R, Bourc'his D et al. A piRNA pathway primed by individual transposons is linked to de novo DNA methylation in mice. Mol. Cell 31(6), 785-799 (2008).

39 Kuramochi-Miyagawa S, Watanabe T, Gotoh K et al. DNA methylation of retrotransposon genes is regulated by Piwi family members MILI and MIWI2 in murine fetal testes. Genes Dev. 22(7), 908-917 (2008).

40 Chotalia M, Smallwood SA, Ruf N et al. Transcription is required for establishment of germline methylation marks at imprinted genes. Genes Dev. 23(1), 105-117 (2009).

41 Fröhlich LF, Mrakovcic M, Steinborn R, Chung U-I, Bastepe M, Jüppner H. Targeted deletion of the Nesp55 DMR defines another Gnas imprinting control region and provides a mouse model of autosomal dominant PHP-Ib. Proc. Natl Acad. Sci. USA 107(20), 9275-9280 (2010).

42 Smith EY, Futtner CR, Chamberlain SJ, Johnstone KA, Resnick JL. Transcription is required to establish maternal imprinting at the Prader-Willi syndrome and Angelman syndrome locus. PLoS Genet. 7(12), e1002422 (2011).

43 Veselovska L, Smallwood SA, Saadeh H et al. Deep sequencing and de novo assembly of the mouse oocyte transcriptome define the contribution of transcription to the DNA methylation landscape. Genome Biol. 16(1), 1-17 (2015).

- Precisely quantitates and functionally tests the relationship between DNA methylation and transcription in oocytes.

44 Smith ZD, Meissner A. DNA methylation: roles in mammalian development. Nat. Rev. Genet. 14(3), 204-220 (2013).

45 Okano M, Bell DW, Haber DA, Li E. DNA methyltransferases Dnmt3a and Dnmt3b are essential for de novo methylation and mammalian development. Cell 99 (3), 247-257 (1999).

46 Bourc'his D, Bestor TH. Meiotic catastrophe and retrotransposon reactivation in male germ cells lacking Dnmt3L. Nature 431(7004), 96-99 (2004).
47 Shirane K, Toh H, Kobayashi H, Miura F, Chiba H, Ito T. Mouse oocyte methylomes at base resolution reveal genomewide accumulation of non-CpG methylation and role of DNA methyltransferases. PLoS Genet. 9(4), e1003439 (2013).

48 Erkek S, Hisano M, Liang C-Y et al. Molecular determinants of nucleosome retention at $\mathrm{CpG}$-rich sequences in mouse spermatozoa. Nat. Struct. Mol. Biol. 20(7), 868-875 (2013).

49 Singh P, Li AX, Tran DA et al. De novo DNA methylation in the male germ line occurs by default but is excluded at sites of H3K4 methylation. Cell Rep. 4(1), 205-219 (2013).

50 Zentner GE, Henikoff S. Regulation of nucleosome dynamics by histone modifications. Nat. Struct. Mol. Biol. 20(3), 259-266 (2013).

51 Noh K-M, Wang H, Kim HR et al. Engineering of a histone-recognition domain in Dnmt3a alters the epigenetic landscape and phenotypic features of mouse ESCs. Mol. Cell 59(1), 89-103 (2015).

52 Vlachogiannis G, Niederhuth CE, Tuna $S$ et al. The Dnmt3L ADD domain controls cytosine methylation establishment during spermatogenesis. Cell Rep. 10(6), 944-956 (2015).

53 Ooi SKT, Qiu C, Bernstein E et al. DNMT3L connects unmethylated lysine 4 of histone $\mathrm{H} 3$ to de novo methylation of DNA. Nature 448(7154), 714-717 (2007).

54 Mikkelsen TS, Ku M, Jaffe DB et al. Genome-wide maps of chromatin state in pluripotent and lineage-committed cells. Nature 448(7153), 553-560 (2007).

55 Kizer KO, Phatnani HP, Shibata Y, Hall H, Greenleaf AL, Strahl BD. A novel domain in Set2 mediates RNA polymerase II interaction and couples histone H3 K36 methylation with transcript elongation. Mol. Cell. Biol. 25(8), 3305-3316 (2005).

56 Edmunds JW, Mahadevan LC, Clayton AL. Dynamic histone $\mathrm{H} 3$ methylation during gene induction: $\mathrm{HYPB} /$ Setd 2 mediates all $\mathrm{H} 3 \mathrm{~K} 36$ trimethylation. EMBO J. 27(2), 406-420 (2008).

57 Hawkins RD, Hon GC, Lee LK et al. Distinct epigenomic landscapes of pluripotent and lineage-committed human cells. Cell Stem Cell 6(5), 479-491 (2010).

58 Du J, Johnson LM, Jacobsen SE, Patel DJ. DNA methylation pathways and their crosstalk with histone methylation. Nat. Rev. Mol. Cell Biol. 16(9), 519-532 (2015).

59 Rose NR, Klose RJ. Understanding the relationship between DNA methylation and histone lysine methylation. Biochim. Biophys. Acta 1839(12), 1362-1372 (2014).

60 Smallwood SA, Kelsey G. De novo DNA methylation: a germ cell perspective. Trends Genet. 28(1), 33-42 (2012).

61 Tsumura A, Hayakawa T, Kumaki Y et al. Maintenance of self-renewal ability of mouse embryonic stem cells in the absence of DNA methyltransferases Dnmt1, Dnmt3a and Dnmt3b. Genes Cells 11(7), 805-814 (2006).

62 Baubec T, Colombo DF, Wirbelauer C et al. Genomic profiling of DNA methyltransferases reveals a role for DNMT3B in genic methylation. Nature 520(7546), 243-247 (2015). 
- A functional examination of the targeting of de novo DNA methyltransferases to the genome by histone modification state.

63 Morselli M, Pastor WA, Montanini B et al. In vivo targeting of de novo DNA methylation by histone modifications in yeast and mouse. eLife 4, e06205 (2015).

64 Dhayalan A, Rajavelu A, Rathert P et al. The Dnmt3a PWWP domain reads histone 3 lysine 36 trimethylation and guides DNA methylation. J. Biol. Chem. 285(34), 26114-26120 (2010).

65 Balhorn R. The protamine family of sperm nuclear proteins. Genome Biol. 8(9), 1-8 (2007).

66 Brykczynska U, Hisano M, Erkek S et al. Repressive and active histone methylation mark distinct promoters in human and mouse spermatozoa. Nat. Struct. Mol. Biol. 17(6), 679-687 (2010).

67 Lesch BJ, Dokshin GA, Young RA, Mccarrey JR, Page DC. A set of genes critical to development is epigenetically poised in mouse germ cells from fetal stages through completion of meiosis. Proc. Natl Acad. Sci. USA 110(40), 16061-16066 (2013).

68 Blackledge NP, Klose RJ. CpG island chromatin: a platform for gene regulation. Epigenetics 6(2), 147-152 (2011).

69 Ciccone DN, Su H, Hevi S et al. KDM1B is a histone H3K4 demethylase required to establish maternal genomic imprints. Nature 461 (7262), 415-418 (2009).

70 Stewart KR, Veselovska L, Kim J et al. Dynamic changes in histone modifications precede de novo DNA methylation in oocytes. Genes Dev. 29(23), 2449-2462 (2015).

- $\quad$ First systematic ChIP-seq study of histone modifications in mammalian oocytes and their role in patterning DNA methylation.

71 Nashun B, Hill Peter WS, Smallwood SA et al. Continuous histone replacement by Hira is essential for normal transcriptional regulation and de novo DNA methylation during mouse oogenesis. Mol. Cell 60(4), 611-625 (2015).

72 Goldberg AD, Banaszynski LA, Noh K-M et al. Distinct factors control histone variant $\mathrm{H} 3.3$ localization at specific genomic regions. Cell 140(5), 678-691 (2010).

73 Li B-Z, Huang Z, Cui Q-Y et al. Histone tails regulate DNA methylation by allosterically activating de novo methyltransferase. Cell Res. 21(8), 1172-1181 (2011).

74 Guo X, Wang L, Li J et al. Structural insight into autoinhibition and histone $\mathrm{H} 3$-induced activation of DNMT3A. Nature 517(7536), 640-644 (2015).

75 Qiu C, Sawada K, Zhang X, Cheng X. The PWWP domain of mammalian DNA methyltransferase Dnmt3b defines a new family of DNA-binding folds. Nat. Struct. Biol. 9(3), 217-224 (2002).

76 Okae $\mathrm{H}$, Chiba $\mathrm{H}$, Hiura $\mathrm{H}$ et al. Genome-wide analysis of DNA methylation dynamics during early human development. PLoS Genet. 10(12), e1004868 (2014).

77 Huntriss J, Hinkins M, Oliver B et al. Expression of mRNAs for DNA methyltransferases and methyl-CpG-binding proteins in the human female germ line, preimplantation embryos, and embryonic stem cells. Mol. Reprod. Dev. 67(3), 323-336 (2004)
78 Kaneda M, Okano M, Hata K et al. Essential role for de novo DNA methyltransferase Dnmt3a in paternal and maternal imprinting. Nature 429(6994), 900-903 (2004).

79 Hata K, Kusumi M, Yokomine T, Li E, Sasaki H. Meiotic and epigenetic aberrations in Dnmt3L-deficient male germ cells. Mol. Reprod. Dev. 73(1), 116-122 (2006).

80 Webster KE, O’Bryan MK, Fletcher $\mathrm{S}$ et al. Meiotic and epigenetic defects in Dnmt3L-knockout mouse spermatogenesis. Proc. Natl Acad. Sci. USA 102(11), 4068-4073 (2005).

81 Zamudio N, Barau J, Teissandier A et al. DNA methylation restrains transposons from adopting a chromatin signature permissive for meiotic recombination. Genes Dev. 29(12), 1256-1270 (2015).

82 Keller TE, Han P, Yi SV. Evolutionary transition of promoter and gene body DNA methylation across invertebrate-vertebrate boundary. Mol. Biol. Evol. 33(4), 1019-1028 (2016).

83 Hata K, Okano M, Lei H, Li E. Dnmt3L cooperates with the Dnmt3 family of de novo DNA methyltransferases to establish maternal imprints in mice. Development 129(8), 1983-1993 (2002).

84 Smith ZD, Chan MM, Mikkelsen TS et al. A unique regulatory phase of DNA methylation in the early mammalian embryo. Nature 484(7394), 339-344 (2012).

85 Borgel J, Guibert S, Li Y et al. Targets and dynamics of promoter DNA methylation during early mouse development. Nat. Genet. 42(12), 1093-1100 (2010).

86 Proudhon C, Duffié R, Ajjan S et al. Protection against de novo methylation is instrumental in maintaining parent-of-origin methylation inherited from the gametes. Mol. Cell 47(6), 909-920 (2012).

87 Rutledge CE, Thakur A, O’Neill KM et al. Ontogeny, conservation and functional significance of maternally inherited DNA methylation at two classes of non-imprinted genes. Development 141(6), 1313-1323 (2014).

88 Duffié R, Ajjan S, Greenberg MV et al. The Gpr1/Zdbf2 locus provides new paradigms for transient and dynamic genomic imprinting in mammals. Genes Dev. 28(5), 463-478 (2014).

89 Branco MR, King M, Perez-Garcia V et al. Maternal DNA methylation regulates early trophoblast development. Dev. Cell 36(2), 152-163 (2016).

-• Shows that oocyte-derived DNA methylation has consequences on gene regulation and development in the conceptus beyond canonical imprinted genes.

90 De La Fuente R, Baumann C, Fan T, Schmidtmann A, Dobrinski I, Muegge K. Lsh is required for meiotic chromosome synapsis and retrotransposon silencing in female germ cells. Nat. Cell Biol. 8(12), 1448-1454 (2006).

91 Chen J, Torcia S, Xie F et al. Somatic cells regulate maternal mRNA translation and developmental competence of mouse oocytes. Nat. Cell Biol. 15(12), 1415-1423 (2013).

92 Guo F, Li X, Liang D et al. Active and passive demethylation of male and female pronuclear DNA in the mammalian zygote. Cell Stem Cell 15(4), 447-458 (2014). 
93 Santos F, Hendrich B, Reik W, Dean W. Dynamic reprogramming of DNA methylation in the early mouse embryo. Dev. Biol. 241(1), 172-182 (2002).

94 Loppin B, Bonnefoy E, Anselme C, Laurencon A, Karr TL, Couble P. The histone H3.3 chaperone HIRA is essential for chromatin assembly in the male pronucleus. Nature 437(7063), 1386-1390 (2005).

95 Torres-Padilla ME, Bannister AJ, Hurd PJ, Kouzarides T, Zernicka-Goetz M. Dynamic distribution of the replacement histone variant $\mathrm{H} 3.3$ in the mouse oocyte and preimplantation embryos. Int. J. Dev. Biol. 50, 455-461 (2006).

96 Amouroux R, Nashun B, Shirane K et al. De novo DNA methylation drives $5 \mathrm{hmC}$ accumulation in mouse zygotes. Nat. Cell Biol. 18(2), 225-233 (2016).

97 Messerschmidt DM, Knowles BB, Solter D. DNA methylation dynamics during epigenetic reprogramming in the germline and preimplantation embryos. Genes Dev. 28(8), 812-828 (2014).

98 Grossniklaus U, Kelly WG, Ferguson-Smith AC, Pembrey M, Lindquist $S$. Transgenerational epigenetic inheritance: how important is it? Nat. Rev. Genet. 14(3), 228-235 (2013).

99 Radford EJ, Ito $\mathrm{M}$, Shi $\mathrm{H}$ et al. In utero undernourishment perturbs the adult sperm methylome and is linked to metabolic disease transmission. Science 345(6198), 1255903-1255903 (2014).

100 Dias BG, Ressler KJ. Parental olfactory experience influences behavior and neural structure in subsequent generations. Nat. Neurosci. 17(1), 89-96 (2014).

101 Carone BR, Fauquier L, Habib N et al. Paternallyinduced transgenerational environmental reprogramming of metabolic gene expression in mammals. Cell 143(7), 1084-1096 (2010)

102 Shea JM, Serra RW, Carone BR et al. Genetic and epigenetic variation, but not diet, shape the sperm methylome. Dev. Cell 35(6), 750-758 (2015).

- An important object lesson for quantifying germline transmission of epigenetic information.

103 Daxinger L, Whitelaw E. Understanding transgenerational epigenetic inheritance via the gametes in mammals. Nat. Rev. Genet. 13(3), 153-162 (2012).

104 Sharma U, Conine CC, Shea JM et al. Biogenesis and function of tRNA fragments during sperm maturation and fertilization in mammals. Science 351(6271), 391-396 (2016).

105 Lane N, Dean W, Erhardt S et al. Resistance of IAPs to methylation reprogramming may provide a mechanism for epigenetic inheritance in the mouse. Genesis 35(2), 88-93 (2003).
106 Nakamura T, Arai Y, Umehara H et al. PGC7/Stella protects against DNA demethylation in early embryogenesis. Nat. Cell Biol. 9(1), 64-71 (2007).

107 Nakamura T, Liu Y-J, Nakashima H et al. PGC7 binds histone $\mathrm{H} 3 \mathrm{~K} 9 \mathrm{me} 2$ to protect against conversion of $5 \mathrm{mC}$ to $5 \mathrm{hmC}$ in early embryos. Nature 486(7403), 415-419 (2012).

- Mechanistic studies on the potential role of histone modifications in the maintenance of gamete-derived DNA methylation in the preimplantation embryo.

108 Terranova R, Yokobayashi S, Stadler MB et al. Polycomb group proteins Ezh2 and Rnf2 direct genomic contraction and imprinted repression in early mouse embryos. Dev. Cell 15(5), 668-679 (2008).

109 Mager J, Montgomery ND, de Villena FP, Magnuson T. Genome imprinting regulated by the mouse Polycomb group protein Eed. Nat. Genet. 33(4), 502-507 (2003).

110 Schroeder DI, Jayashankar K, Douglas KC et al. Early developmental and evolutionary origins of gene body DNA methylation patterns in mammalian placentas. PLoS Genet. 11(8), e1005442 (2015).

111 Umlauf D, Goto Y, Cao R et al. Imprinting along the Kcnq1 domain on mouse chromosome 7 involves repressive histone methylation and recruitment of Polycomb group complexes. Nat. Genet. 36(12), 1296-1300 (2004).

112 Lewis A, Green K, Dawson C et al. Epigenetic dynamics of the Kcnq1 imprinted domain in the early embryo. Development 133(21), 4203-4210 (2006).

113 Wagschal A, Sutherland HG, Woodfine K et al. G9a histone methyltransferase contributes to imprinting in the mouse placenta. Mol. Cell. Biol. 28(3), 1104-1113 (2008).

114 Santos F, Peters AH, Otte AP, Reik W, Dean W. Dynamic chromatin modifications characterise the first cell cycle in mouse embryos. Dev. Biol. 280 (1), 225-236 (2005).

115 Van Der Heijden GW, Dieker JW, Derijck AA. Asymmetry in histone $\mathrm{H} 3$ variants and lysine methylation between paternal and maternal chromatin of the early mouse zygote. Mech. Dev. 122, 1008-1022 (2005).

116 Puschendorf M, Terranova R, Boutsma E et al. PRC1 and Suv39h specify parental asymmetry at constitutive heterochromatin in early mouse embryos. Nat. Genet. 40(4), 411-420 (2008).

117 Smith ZD, Chan MM, Humm KC et al. DNA methylation dynamics of the human preimplantation embryo. Nature 511(7511), 611-615 (2014).

118 Guo H, Zhu P, Yan L et al. The DNA methylation landscape of human early embryos. Nature 511(7511), 606-610 (2014). 